\title{
Pembelajaran IPA Terpadu Tipe Integrated Melalui Model Inkuiri Terbimbing Tingkat Sekolah Menengah Pertama
}

\author{
Diniya \\ Program Studi Tadris IP A, Universitas Islam Negeri Sultan Syarif Kasim Riau \\ e-mail: \\ diniya@uin-suska.ac.id
}

\begin{abstract}
.
The changes made by the Government in the 2013 curriculum are learning that uses a scientific approach, studentcentered learning, integrated learning, developing students 'thinking abilities, instilling spiritual and social attitudes, and exploring students' communication and collaboration skills. Based on a literature review, there are still many schools that teach science partially. It turns out that there are many obstacles faced by teachers during the process of implementing science learning in an integrated manner and one of them is the teacher's difficulty in designing integrated science learning models. The data collection process carried out by the author is based on a literature study in the form of journals and books which are then analyzed and synthesized. The purpose of this literature review is to propose an integrated science learning model that can be used by teachers in their implementation in the classroom, namely the integrated type that can be supported by using the guided inquiry learning model during the learning process. Based on the results of the analysis of 16 journals and 10 books, it can be seen that the guided inquiry model is considered suitable for integrated type learning because it is able to explore students' knowledge in various disciplines through investigation in which there are experimental activities and communicating through discussion.
\end{abstract}

Keywords: learning design, integrated science integrated type, guided inquiry learning model.

\begin{abstract}
ABSTRAK.
Perubahan-perubahan yang dilakukan oleh Pemerintah dalam kurikulum 2013 adalah pembelajaran yang menggunakan pendekatan saintifik, pembelajaran yang berpusat pada siswa, pembelajaran terpadu, mengembangkan kemampuan berpikir siswa, menanamkan sikap spiritual dan sosial, dan menggali kemampuan komunikasi serta kolaborasi siswa. Berdasarkan kajian literatur, masih banyak sekolah yang mengajarkan IPA secara parsial. Ternyata ada banyak kendala yang dihadapi oleh guru selama proses pelaksanaan pembelajaran IPA secara terpadu dan salah satunya adalah guru kesulitan merancang pembelajaran model IPA terpadu. Adapun proses pengumpulan data yang dilakukan oleh penulis adalah berdasarkan studi pustaka berupa jurnal dan buku yang kemudian dianalisis dan disintesis. Adapun tujuan dari kajian literatur ini adalah mengajukan satu model pembelajaran IPA terpadu yang dapat digunakan guru dalam pelaksanannya di kelas yaitu tipe integrated yang dapat didukung dengan menggunakan model pembelajaran inkuiri terbimbing selama proses pembelajarannya. Berdasarkan hasil analasis 16 jurnal dan 10 buku dapat diketahui bahwa model inkuiri terbimbing dianggap sesuai untuk pembelajaran tipe integrated karena mampu menggali pengetahuan siswa di berbagai displin ilmu melalui penyelidikan yang di dalamnya terdapat kegiatan eksperimen dan mengomunikasikan melalui diskusi.
\end{abstract}

Kata kunci: rancangan pembelajaran, IPA terpadu tipe integrated, model pembelajaran inkuiri terbimbing 


\section{PENDAHULUAN}

Pengembangan kurikulum yang terus dilakukan dalam dunia pendidikan di Indonesia disebabkan oleh semakin pesatnya tantangan zaman di abad 21. Melalui pengembangan kurikulum yang sesuai dengan tantangan abad 21, diharapkan akan mencetak generasi yang mampu bersaing baik secara nasional ataupun internasional. Adapun pengembangan kurikulum berlandaskan prinsip-prinsip berikut ini 1) berpusat pada potensi, pengembangan, kebutuhan dan kepentingan peserta didik dan lingkungannya, 2) beragam dan terpadu, 3) tanggap terhadap perkembangan ilmu pengetahuan, teknolohi dan seni, 4) relevan dengan kebutuhan hidup, 5) menyeluruh dan berkesinambungan, 6) belajar sepanjang hayat, dan 7) seimbang antara kepentingan nasional dan daerah. Salah satu pengembangan yang begitu membutuhkan perhatian adalah semua mata pelajaran berdiri sendiri secara terpisah menjadi mata pelajaran terikat satu sama lain dengan mendukung kompetensi inti. Hal ini dapat dikatakan bahwa mata pelajaran menjadi terintegrasi seperti mata pelajaran IPA yang tidak lagi diajarkan secara terpisah baik kimia, fisika, biologi dan IPBA. Standar isi dalam kurikulum 2013 (BNSP, 2016) mengamanatkan bahwa mata pelajaran IPA SMP dikembangkan sebagai mata pelajaran integrative science, berorientasi aplikatif, pengembangan kemampuan berpikir, kemampuan belajar, rasa ingin tahu, dan sikap peduli dan tanggung jawab terhadap lingkungan alam. Beberapa ahli berpendapat bahwa pembelajaran IPA terpadu merupakan gabungan dari beberapa disiplin ilmu yaitu antara fisika, biologi, kimia dan IPBA. Hal ini sesuai dengan pernyataan Trianto (2007) bahwa pembelajaran terpadu adalah pembelajaran yang diawali dengan suatu pokok bahasan atau tema tertentu yang dikaitkan dengan pokok bahasan lain, konsep tertentu dikaitkan dengan konsep lain, yang diberlakukan secara spontan atau direncanakan, baik dalam satu bidang studi atau lebih, dengan beragam pengalaman belajar anak, sehingga pembelajaran jadi bermakna.menyebutkan tujuan pembelajaran IPA secara khusus bertujuan mengembangkan siswa untuk memiliki sikap ilmiah: rasa ingin tahu, logis, kritis, analitis, jujur, dan tanggung jawab melalui IPA. Siswa juga diharapkan akan mengajukan pertanyaan tentang fenomena IPA, melaksanakan percobaan, mencatat dan menyajikan hasil penyelidikan dalam bentuk tabel dan grafik, menyimpulkan, serta melaporkan hasil penyelidikan secara lisan maupun tertulis untuk menjawab pertanyaan tersebut. Selain itu juga siswa diharapkan untuk memahami konsep dan prinsip IPA serta saling keterkaitannya dan diterapkan dalam menyelesaikan masalah. Tujuan tersebut memiliki proses pemerolehan yang berbeda sesuai dengan kompetensi yang ingin dicapai. Sikap dibentuk melalui aktivitas-aktivitas: menerima, menjalankan, menghargai, menghayati, dan mengamalkan. Pengetahuan dimiliki melalui aktivitas-aktivitas diantaranya mengetahui, memahami, menerapkan, menganalisis, mengevaluasi, dan mencipta. Keterampilan diperoleh melalui aktivitas-aktivitas: mengamati, menanya, mencoba, menalar, menyaji, dan mencipta.

Pada kenyataannya, pelaksanaan pembelajaran IPA di beberapa sekolah masih terpisahpisah. Hal ini sesuai dengan permasalahan dalam penelitian Dewi, Sadia, dan Ristiati (2013, hlm. 1) bahwa pembelajaran IPA masih dilakukan secara parsial. Konsep secara terpadu yang dimaksudkan belum tercermin pada proses pelaksanaan pembelajaran di kelas. Permasalahan yang sama juga diungkapkan dalam observasi penelitian yang dilakukan oleh Muhafid, Dewi dan Widiyatmoko (2013) di SMPN 3 Satu Atap Ayah bahwa pembelajaran IPA terpadu di sekolah tersebut belum terlaksana. Hasil wawancara yang dilakukan oleh Aini, Tukiran, dan Qosyim (2013) di SMPN 1 Madiun bahwa pembelajaran IPA terpadu belum dilakukan secara maksimal dan berdasarkan hasil angket yang diberikan pada siswa bahwa pembelajaran IPA terpadu di SMP tersebut masih diajarkan secara terpisah antara fisika dan biologi. Secara umum, ada beberapa kendala yang dialami oleh guru dalam menerapkan pembelajaran IPA terpadu antara lain: 1) kesiapan guru, selama ini guru IPA berlatarbelakang disiplin ilmu yang memang terpisah atau berbeda-beda baik fisika, biologi maupun kimia saja, 2) masih terbatasnya perangkat pembelajaran, media atau sumber belajar seperti buku ajar cetak yang memuat konsep-konsep IPA secara terpadu baik untuk buku pegangan bagi guru maupun siswa, dan 3) kesulitan memadukan konsep-konsep 
IPA sehingga menjadi suatu pembelajaran terpadu (Muhafid, dkk., 2013; Aini, dkk., 2013). Oleh karena itu, diperlukannya suatu model pembelajaran IPA terpadu yang sifatnya dapat mengintegrasikan konsep-konsep sains.

Prabowo (dalam Trianto, 2007) menjelaskan bahwa langkah pembelajaran terpadu sama seperti model pembelajaran yang lain, meliputi tahap perencanaan, tahap pelaksanaan, dan tahap evaluasi. Sintaks dalam pembelajaran terpadu dapat diakomodasikan dari berbagai model pembelajaran sehingga pembelajaran terpadu bersifat luwes dan fleksibel. Tentunya sangat penting menerapkan model pembelajaran terpadu karena suatu pendekatan belajar mengajar yang melibatkan beberapa bidang studi dapat memberikan pengalaman belajar yang bermakna bagi siswa (Karli, 2003). Menurut Prabowo dalam Rosidi (2015) bahwa pembelajaran terpadu adalah suatu proses pembelajaran yang melibatkan berbagai bidang studi. Pembelajaran terpadu ini dapat melibatkan siswa secara aktif selama pembelajaran berlangsung. Adapun ciri pembelajaran terpadu adalah 1) pembelajaran terpusat pada siswa, 2) meaningful learning, 3) belajar melalui pengalaman langsung, 4) menekankan pada proses penemuan pengetahuan, dan 5) keterkaitan antar bidang studi akan membantu mengembangkan kemampuan berpikir kritis siswa (Rosidi, 2015). Oleh karena itu, salah satu upaya yang dapat dilakukan oleh guru agar terlaksananya pembelajaran IPA secara terpadu maka dapat menggunakan pembelajaran IPA Terpadu tipe terintegrasi penuh (integrated).

Menurut Fogarty (1991) bahwa pembelajaran IPA tipe integrated adalah model pembelajaran IPA terpadu yang merepresentasikan berbagai disiplin ilmu (cross disciplinary). Karakteristik dari tipe integrated ini adalah 1) model integrasi yang dapat meleburkan semua disiplin dalam IPA dengan memilih prioritas dari masing-masing disiplin, 2) dapat menemukan overlapping skills, konsep, dan sikap dari semua disiplin tersebut, dan 3) diperlukannya tim yang mampu menyusun kurikulum dengan baik dan tepat. Pada tipe integrated ini tidak hanya mengajak siswa menguasai konsep secara terpadu namun juga mengembangkan keterampilan dan sikap selama pembelajaran.

Adapun keterampilan yang dapat dilatihkan adalah keterampilan proses sains berupa mengamati, mengukur, mencatat data, menginterpretasi, mengklasifikasi, menggunakan alat, merancang dan melakukan eksperimen, menarik kesimpulan dan mengomunikasikan. Sikap yang dapat ditanamkan selama pembelajaran pada tipe integrated adalah keingintahuan, kolaboratif, ketelitian, kejujuran, keterbukaan, kebersihan, memelihara kesehatan dan peduli lingkungan. Dari sejumlah model pembelajaran IPA terpadu yang dikemukakan Fogarty (dalam Anjarsari, 2013) bahwa terdapat empat model yang potensial untuk diterapkan dalam pembelajaran IPA terpadu, yaitu connected, webbed, shared, dan integrated. Empat model tersebut pilih karena konsep-konsep dalam Kompetensi Dasar (KD) IPA memiliki karakteristik yang berbeda-beda, sehingga memerlukan model yang sesuai agar memberikan hasil yang optimal. Berdasarkan penjabaran di atas penulis memilih tipe keterpaduan pembelajaran IPA yang akan dirancang adalah tipe integrated untuk tingkat SMP. Tipe keterpaduan ini dipilih agar materi satu sama lain tidak saling tumpang tindih dan mengurangi jumlah materi pembelajaran. Selain itu tipe keterpaduan integrated dapat mengembangkan kemampuan berpikir tingkat tinggi yaitu kemampuan berpikir analisis, kritis, kreatif dan pemecahan masalah. Di sekolah, tipe integrated juga dapat dipilih untuk diterapkan pada pelaksanaan pembelajaran IPA agar terciptanya kebersamaan guru antardisiplin dalam merencanakan dan melaksanakan pembelajaran.

\section{METODOLOGI}

Adapun metode yang digunakan dalam tulisan ini berupa kajian literatur (literature review) yang terdiri dari jurnal dan buku. Ditambah pula dokumen penulis berupa rancangan pembelajaran IPA Terpadu Tipe Integrated. Beberapa pembahasan yang terkait dengan Rancangan Pembelajaran IPA Terpadu Tipe Integrated melalui Model Pembelajaran Inkuiri Terbimbing dianalisis dan 
disintesis. Analisis terkait rancangan pembelajaran IPA Terpadu Tipe Integrated melibatkan analisis silabus dan materi yang sesuai dengan topik IPA tingkat Sekolah Menengah Pertama (SMP).

\section{TEMUAN DAN PEMBAHASAN}

Pemilihan konsep-konsep terkait yang akan diajarkan pada pembelajaran IPA terpadu tipe integrated harus terlebih dahulu dilakukan analisis silabus. Kemudian memilih materi yang saling terkait antara ata pelajaran fisika, biologi dan kimia. Adapun berdasarkan hasil analisis silabus didapat beberapa materi yang dapat digunakan pada pembelajaran IPA Terpadu Tipe Integrated antara lain bentuk energi, sumber energi, perubahan bentuk energi, gerak tumbuhan, jaringan pada tumbuhan dan unsur-unsur kimia penyusun air dan matahari.

Model integrated (Karli, 2003) menyebutkan bahwa menggabungkan beberapa disiplin ilmu dalam menemukan konsep melalui keterampilan proses dengan menggunakan model ini dapat memudahkan para peneliti dan guru yang ingin menerapkannya dalam pembelajaran di kelas. Adapun displin ilmu yang akan digabungkan adalah biologi, fisika dan kimia. Disiplin ilmu tersebut diambil karena tema pembelajaran yang direncanakan berjudul "Pentingnya Sinar Matahari Bagi Tumbuhan". Siswa tidak hanya akan diajarkan konsep- konsep yang terkait namun siswa juga akan dilatih keterampilan proses sains berupa merancang dan melakukan eksperimen serta mengomunikasikan. Sikap yang akan ditanamkan dalam diri siswa adalah sikap kolaboratif. Kemendikbud (2017) menyatakan bahwa dalam mencapai tujuan pendidikan nasional dan menghadapi tantangan abad 21 pada pembelajaran IPA diharapkan siswa memenuhi kemampuan keterampilan belajar dan inovasi yang meliputi kemampuan berpikir dan mampu menyelesaikan masalah, kreatif dan inovatif, serta mampu berkomunikasi dan berkolaborasi. Oleh karena itu, pembelajaran hendaknya diarahkan untuk melatih kemampuan komunikasi dan kolaborasi agar siswa dapat berkontribusi bagi masyarakat. Kontribusi berupa ilmu yang sudah di dapat selama pembelajaran di sekolah dan diterapkan dalam masyarakat melalui kemampuan komunikasi dan kolaborasi yang mendukungnya. Adapun desain unit IPA terpadu tipe integrated dapat dilihat pada gambar berikut ini:

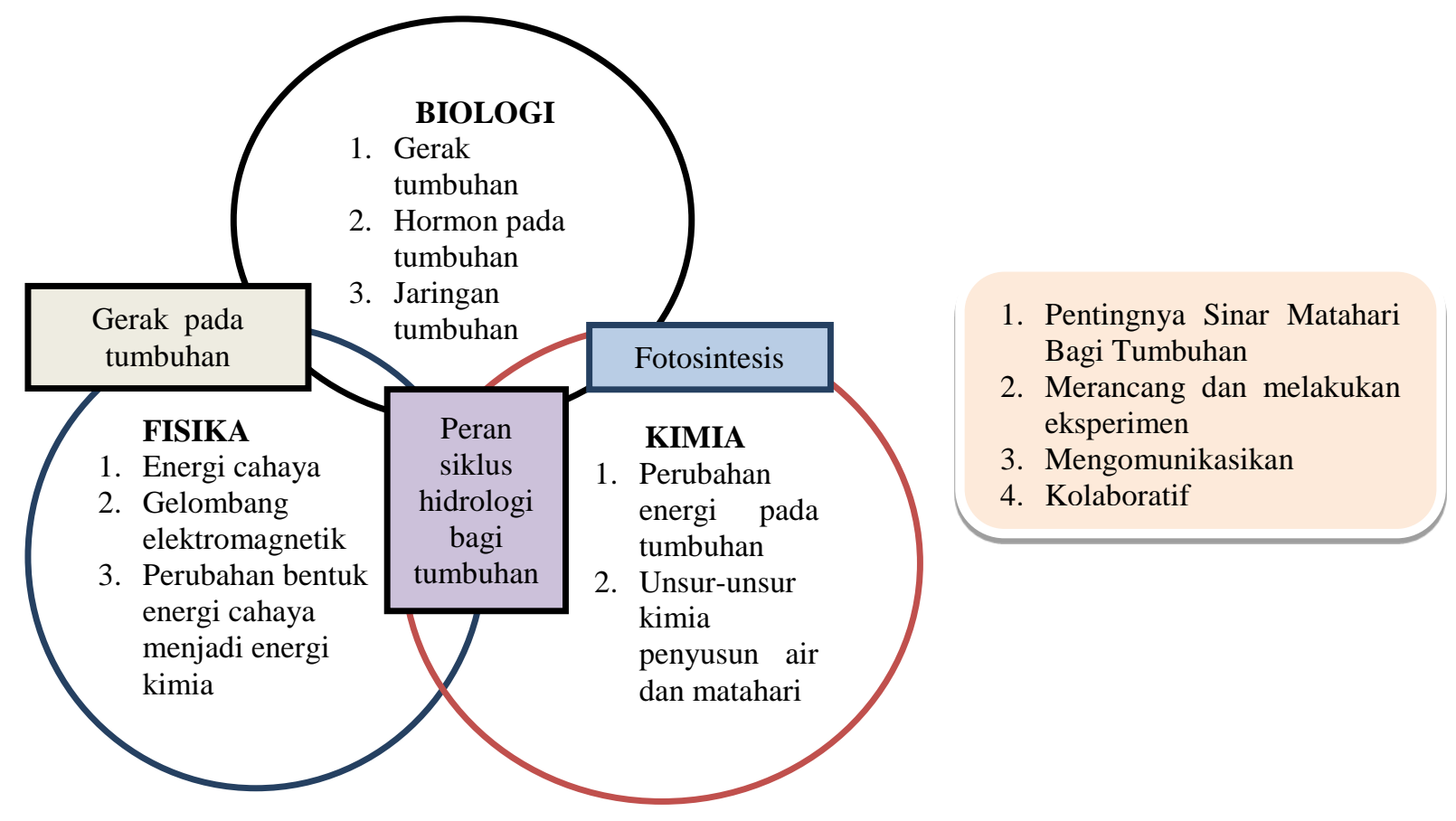

Gambar 1. Desain IPA Terpadu Tipe Integrated 
Adapun organisasi pembelajaran IPA terpadu tipe integrated dapat dilihat pada gambar 2 berikut ini:

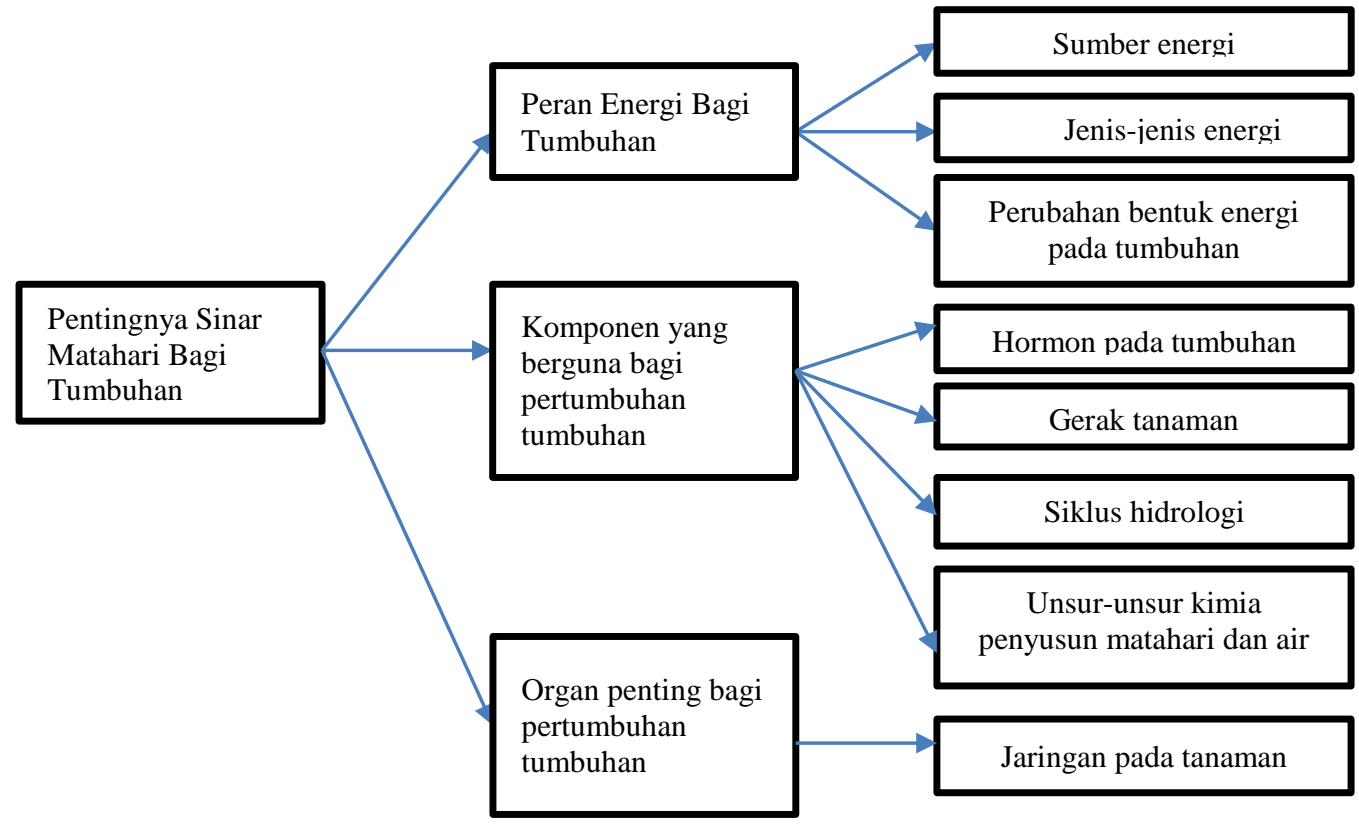

Gambar 2. Organisasi Pembelajaran IPA Terpadu Tipe Integrated

\section{Strategi Pembelajaran}

Sufairoh (2016) menyatakan strategi pembelajaran adalah suatu pola atau desain secara umum dari suatu pembelajaran yang disusun secara sistematis berdasarkan prinsip-prinsip pendidikan, psikologi didaktik dan komunikasi dengan mengintegrasikan struktur, metode, media/alat peraga pembelajaran, pengelolaan kelas, evaluasi dan waktu yang dibutuhkan untuk mencapai tujuan pembelajaran.

\section{Tujuan pembelajaran}

1. Menyelidiki pengaruh sinar matahari dan banyaknya jumlah air terhadap pertumbuhan tanaman melalui percobaan.

2. Mengomunikasikan pentingnya sinar matahari dan banyaknya jumlah air bagi tumbuhan melalui diskusi.

\section{Indikator}

Adapun indikator pembelajaran terkait tema antara lain:

1. Siswa dapat menjelaskan jenis gerak tumbuhan danmemberikan contoh

2. Siswa dapat menjelaskan macam-macam hormon pada tumbuhan beserta fungsinya

3. Siswa dapat mengklasifikasikan jaringan pada tumbuhan

4. Siswa dapat mendeskripsikan manfaat energi cahaya bagitumbuhan

5. Siswa dapat menjelaskan perubahan bentuk energi cahaya

6. Siswa dapat menyebutkan macam-macam gelombang elektromagnetik

7. Siswa dapat menentukan unsur-unsur kimia penyusun air dan matahari

8. Siswa dapat merancang eksperimen terkait pentingnya sinar matahari bagi tumbuhan

9. Siswa dapat mengomunikasikan hasil eksperimen di depankelas 
Berikut ini merupakan rancangan strategi pembelajaran pada IPA Terpadu tipe Integrated.

Tabel 1. Rancangan Strategi Pembelajaran IPA Terpadu Tipe Integrated

\begin{tabular}{ccc}
\hline Model Pembelajaran & Pendekatan Pembelajaran & Metode Pembelajaran \\
\hline Inkuiri Terbimbing & Pendekatan Saintifik & Metode Eksperimen \\
\hline & Pendekatan Prosedural & Metode Diskusi \\
\hline
\end{tabular}

\section{Pendekatan Pembelajaran}

Pendekatan pembelajaran adalah suatu rangkaian tindakan pembelajaran yang dilandasi oleh prinsip dasar tertentu (filosofis, psikologis, didaktis dan ekologis) yang mewadahi, menginspirasi, menguatkan dan melatari metode pembelajaran tertentu (Kementerian Pendidikan dan Kebudayaan, 2016). Pembelajaran dengan pendekatan saintifik adalah proses pembelajaran yang dirancang sedemikian rupa agar peserta didik secara aktif mengonstruk konsep, hukum atau prinsip melalui tahapan-tahapan mengamati (untuk mengidentifikasi atau menemukan masalah), merumuskan masalah, mengajukan atau merumuskan hipotesis, mengumpulkan data dengan berbagai teknik, menganalisis data, menarik kesimpulan dan mengomunikasikan konsep, hukum atau prinsip yang "ditemukan". Pendekatan saintifik dimaksudkan untuk memberikan pemahaman kepada peserta didik dalam mengenal, memahami berbagai materi menggunakan pendekatan ilmiah, bahwa informasi bisa berasal dari mana saja, kapan saja, tidak bergantung pada informasi searah dari guru. Oleh karena itu kondisi pembelajaran yang diharapkan tercipta diarahkan untuk mendorong peserta didik dalam mencari tahu dari berbagai sumber melalui observasi, dan bukan hanya diberi tahu (Sufairoh, 2016).

Permasalahan dalam pembelajaran IPA dapat ditemukan solusinya melalui adanya pengetahuan secara konseptual dan prosedural. Pengetahuan konseptual adalah pengetahuan tentang ide-ide dan teori sedangkan pengetahuan prosedural adalah pengetahuan tentang bagaimana menerapkan konsep yang sudah dipelajari untuk mengatasi permasalahan yang diberikan (Surif, Ibrahim, \& Mokhtar, 2012). Agar pengetahuan prosedural ini dapat tercapai maka diperlukannya pendekatan prosedural selama pembelajaran IPA.

\section{Pendekatan Pembelajaran}

Model pembelajaran adalah suatu perencanaan atau pola yang digunakan sebagai pedoman dalam merencanakan pembelajaran di kelas (Trianto, 2007). Selain itu, model pembelajaran yang digunakan di dalam kelas selama pembelajaran diharapkan dapat membantu siswa untuk mendapatkan ide, informasi, keterampilan, cara berpikir dan mengekspresikan ide sehingga tercapainya tujuan pembelajaran (Joyce \& Well, 1992). Salah satu model pembelajaran yang dapat membantu siswa menyelidiki permasalahan, mengomunikasikan dan mengembangkan kemampuan berpikir adalah model inkuiri terbimbing. Abdi, 2014; Avsec dan Kocijancic, 2014; Maxwell, Lambeth dan Cox, 2015; Subarkah \& Winayah, 2015, menyatakan bahwa pembelajaran inkuiri dalam sains sangatlah penting karena dalam pembelajarannya menuntun siswa menemukan sesuatu melalui suatu kegiatan penyelidikan. Adapun mengajar melalui model inkuiri memberikan dampak yang besar untuk meningkatkan kemampuan berpikir kritis siswa (Azizmalayeri, 2013; Duran, 2016; Kazempour, 2013; Maxwell, Lambeth, \& Cox, 2015; Server \& Guven, 2014; Subarkah \& Winayah, 2015; Zuiker \& Whitake, 2014).

Pada tahapan awal pembelajaran inkuiri, siswa akan dihadapkan dengan permasalahan yang ada dalam dunia nyata, melihat informasi dan menemukan ide-ide baru yang berhubungan dengan peristiwa serta belajar menemukan solusi permasalahan melalui kegiatan penyelidikan dan pemberian alasan- alasan yang bersifat saintifik (Avsec \& Kocijancic, 2014; Duran, 2016; Kelly, et.al, 2013; Server \& Guven, 2014). 
Proses menemukan solusi dari permasalahan atau fenomena melalui serangkaian kegiatan penyelidikan bukan dilakukan dengan sesuka hati. Akan tetapi kegiatan penyelidikan haruslah melalui proses pemikiran ilmiah. Sesuai dengan yang dinyatakan oleh (Azizmalayeri, 2013; Duran, 2016; Kazempour, 2013) bahwa pembelajaran berbasis inkuiri memimpin siswa secara langsung kepada proses pemikiran ilmiah dan ini dapat dicapai melalui penekanan proses ilmiah selama proses penyelidikan berlangsung. Dengan adanya, proses ilmiah ini akan melatih siswa menemukan alasan-alasan saintifik. Apabila siswa diizinkan untuk melakukan kegiatan penyelidikan maka mereka dapat menggabungkan pengetahuan baru ke dalam pemahaman mereka dengan baik (Maxwell, Lambeth, \& Cox, 2015). Hal itu dikarenakan siswa mengalami secara langsung selama proses pembelajaran menemukan pengetahuan baru.

Selaras dengan pernyataan (Azizmalayeri, 2013) bahwa pendekatan inkuiri menghasilkan peningkatan pemahaman tentang ilmu pengetahuan, peningkatan prestasi akademik, lebih meningkatkan penggunaan berpikir kritis. Pembelajaran berbasis inkuiri (IBL) dianggap penting dikarenakan berfokus kepada pembelajaran yang berpusat pada siswa (Duran, 2016) dan dapat membantu siswa menjadi seorang pembelajar yang aktif (Avsec \& Kocijancic, 2014; Maxwell, Lambeth \& Cox, 2015). Dengan demikian, secara umum dapat disimpulkan bahwa langkahlangkah pembelajarn inkuiri antara lain 1) orientasi, 2) merumuskan masalah, 3) merumuskan hipotesis, 4) mengumpulkan data, 5) menguji hipotesis, dan 6) merumuskan kesimpulan (Azizmalayeri, 2013; Duran, 2016; Kazempour, 2013; Kemendikbud, 2016; Maxwell, Lambeth, \& Cox, 2015; Server \& Guven, 2014; Subarkah \& Winayah, 2015; Zuiker \& Whitake, 2014).

Terdapat beberapa pengelompokan mengenai tipe dan tahapan pembelajaran inkuiri menurut Colburn (2000) sebagaimana tercantum pada Tabel 2.

Tabel 2. Tahap Pembelajaran berbasis Inquiry

\begin{tabular}{|c|c|c|}
\hline Structured Inquiry & Guided Inquiry & Free Inquiry \\
\hline $\begin{array}{l}\text { Siswa mengikuti dengan tepat } \\
\text { instruksi guru untuk }\end{array}$ & $\begin{array}{ll}\text { Siswa mengembangkan cara } \\
\text { kerja untuk menyelidiki }\end{array}$ & $\begin{array}{l}\text { Siswa menurunkan pertanyaan } \\
\text { tentang topik yang dipilih guru }\end{array}$ \\
\hline $\begin{array}{l}\text { menyelesaikan kegiatan hands- } \\
\text { on dengan sempurna }\end{array}$ & $\begin{array}{l}\text { pertanyaan } \\
\text { dipilih/diberikan guru }\end{array}$ & $\begin{array}{l}\text { dan Merencanakan sendiri } \\
\text { penyelidikannya }\end{array}$ \\
\hline
\end{tabular}

Penelitian telah banyak dilakukan terkait penerapan model pembelajaran berbasis inkuiri terbimbing. Syafaren, A., Yustina, Y., \& Mahadi, I. (2019) menyatakan penggunaan integrasi inkuiri terbimbing dengan numbered heads together dalam proses pembelajaran dapat meningkatkan motivasi belajar peserta didik. Selain itu, Sukini, (2019) menyatakan bahwa penerapan pembelajaran guided inquiry berbasis pendekatan saintifik dapat meningkatkan aktivitas dan hasil belajar kognitif biologi siswa.

Tahapan lain dalam pembelajaran berbasis inkuiri yang dijelaskan oleh Wenning (2005b) dalam lima tahapan yang ditunjukkan pada Tabel 3 yang didasarkan pada tingkat pengalaman intelektual serta frekuensi keterlibatan guru dan siswa dalam kegiatan pembelajaran.

Tabel 3. Tahapan dalam Pembelajaran Berbasis Inkuiri

\begin{tabular}{ccccc}
\hline $\begin{array}{c}\text { Discovery } \\
\text { Learning }\end{array}$ & $\begin{array}{c}\text { Interactive } \\
\text { Demonstration }\end{array}$ & Inquiry Lesson & Inquiry Lab & Hypothetical Inquiry \\
\hline Rendah & Kecerdasan Intelektual & Tinggi \\
\hline Guru & & Keterlibatan & Siswa
\end{tabular}

\section{Metode yang digunakan}

Metode yang akan digunakan selama pembelajaran adalah metode eksperimen dan metode diskusi. Djamarah dan Zain (2006) bahwa metode eksperimen adalah cara penyajian pelajaran dimana siswa melakukan percobaan secara langsung dan membuktikan sendiri sesuatu yang 
dipelajari. Metode diskusi adalah suatu metode yang dilakukan melalui tanya jawab dengan tujuan menggali kemampuan bernalar dan berpikir siswa.

\section{Langkah-langkah pembelajaran}

Berikut ini adalah rancangan langkah-langkah pembelajaran berbasis inkuiri terbimbing:

\section{Orientasi}

Siswa mengamati permasalahan yang diajukan oleh guru terkait tumbuhan cabai yang dapat tumbuh dengan subur.

2. Merumuskan masalah

Siswa merumuskan permasalahan melalui proses bertanya dan memberikan argumen berdasarkan pengetahuan awalnya mengenai permasalahan bagaimana bibit cabai dapat menjadi tumbuhan yang subur.

3. Merumuskan hipotesis

Siswa menuliskan hipotesisnya mengenai permasalahan tersebut pada kolom yang sudah disediakan pada Lembar Kerja Peserta Didik (LKPD).

4. Mengumpulkan data

a. Siswa merancang percobaan secara berkelompok yang berjudul "Pengaruh Sinar Matahari dan Air Bagi Pertumbuhan Tanaman Cabai".

b. Siswa melakukan percobaan secara berkelompok tentang pengaruh sinar matahari dan air bagi pertumbuhan bibit cabe.

c. Siswa mengambil data dari percobaan yang telah dilakukan dalam bentuk tabel dan grafik (variabel: intensitas cahaya matahari dan banyaknya penyiraman).

\section{Menguji hipotesis}

Siswa berdiskusi terkait data hasil percobaan yang sudah dilakukan sehingga menemukan jawaban untuk permasalahan yang diajukan. (Metode diskusi)

6. Merumuskan kesimpulan

Siswa memberikan kesimpulan dan mempresentasikan hasil pengamatan yang sudah dilakukan.

\section{Asesmen Formatif}

Ada beberapa jenis asesmen berdasarkan tujuan dalam pembelajaran berbasis inkuiri antara lain asesmen diagnostik, asesmen formatif, asesmen sumatif dan asesmen komparatif. Asesmen formatif yang dapat digunakan untuk mendukung pembelajaran sehari-hari dan menggunakan semua aktivitas normal di suatu kelas. Asesmen formatif pada pembelajaran IPA berbasis inkuiri haruslah didukung dengan proses pembelajaran yang sesuai dengan cara menanyakan siswa beberapa kali selama suatu unit pembelajaran, mengamati suatu kegiatan, membuat grafik atau membuat suatu argumen terhadap suatu topik (Rustaman, N 2007). Lebih lanjut lagi Rustaman, N (2003) menyatakan proses belajar mengajar berbasis inkuiri dianjurkan untuk menggunakan pertanyaan-pertanyaan yang produktif sehingga menstimulus siswa melakukan kegiatan yang produktif. Dalam bentuk tes tertulis, bentuk asesmen untuk pembelajaran IPA berbasis inkuiri dapat dikonstruk dalam butir soal keterampilan proses sains (KPS). Soal dikonstruk secara khusus karena berbeda dengan soal penguasaan konsep. Butir soal KPS meminta siswa untuk mengolah informasi yang ada dan ditampilkan (berupa informasi verbal dan visual, data dalam tabel, diagram atau grafik) dan pertanyaan yang perlu digunakan adalah pertanyaan yang bersifat produktif. Selain itu, Yunita (dalam Rustaman,2007) juga menambahkan bahwa masih ada berbagai cara yang dapat dilakukan untuk melakukan evaluasi kegiatan laboratorium seperti tes praktikum, tes prestasi, observasi langsung, menulis laporan konferensi individu dan konferensi kelompok. 


\section{SIMPULAN}

Berdasasarkan hasil kajian literatur dan rancangan pembelajaran di atas maka dapat disimpulkan bahwa model pembelajaran IPA terpadu tipe integrated dapat mendukung pembelajaran IPA dalam mengintegrasikan konsep-konsep sehingga tidak lagi adanya pembelajaran dengan konsep yang terpisah-pisah. Selain itu pembelajaran IPA tipe integrated akan mengurangi adanya konsep yang bersifat tumpang tindih (overlapping). Pembelajaran IPA terpadu ini dapat didukung dengan penggunaan model pembelajaran inkuiri terbimbing melalui metode eksperimen dan diskusi selama pelaksanaannya di kelas. Adapun asesmen formatif yang dapat disusun berupa soal tes tulis dengan komponen keterampilan proses sains. Di samping itu guru juga dapat menambahkan asesmen lainnya untuk membantu penilaian seperti laporan praktikum dan keterampilan siswa dalam mengomunikasikan hasil praktikum.

\section{REFERENSI}

Abdi, A. (2014). The Effect of Inquiry-Based Learning Method on Students' Academic Achievement in Science Course. Universal journal of educational Research, 2(1), 37-41.

Aini, N., Turkiran. \& Qosyim, A. (2013). Model Penemuan Terbimbing (Guided Discovery) Pada Pembelajaran IPA Terpadu Tipe Webbed dengan Tema Biopestisida. Jurnal Pendidikan Sains e-Press, 1(2). 118-122.

Anjarsari, P. (2013). Pengembangan Pembelajaran IPA Terpadu. Makalah disampaikan dalam PPM "Workshop Pengembangan Perangkat Pembelajaran Sains Terpadu Untuk Meningkatkan Kognitif, Keterampilan Proses, Kreativitas serta Menerapkan Konsep Ilmiah Siswa SMP”. Universitas Negeri Yogyakarta.

Avsec, S., \& Kocijancic, S. L. A. V. K. O. (2014). Effectiveness of inquiry-based learning: How do middle school students learn to maximise the efficacy of a water turbine. International journal of engineering education, 30(6), 1436-1449.

Azizmalayeri, K. (2013). The Impact of Guided Inquiry Methods of Teaching on The Critical Thinking of High School Students. Journal of Education and Practice.

Dewi, K., Sadia, I. W. \& Ristiati, N. P. (2013). Pengembangan Perangkat Pembelajaran IPA Terpadu dengan Setting Inkuiri Terbimbing Untuk Meningkatkan Pemahaman Konsep dan Kinerja Ilmiah Siswa. E-Journal Program Pascasarjana Universitas Pendidikan Ganesha, 3. $1-11$.

Dillashaw, F. G. \& Okey, J. R. (1980). Test of the Integrated Scienc Process Skills for Secondary Science Students. Science Education, 64 (5). 601-608.

Doran, R., Chan, F., Tamir. P. \& Lenhardt, C. (2002). Science Educator's Guide to Laboratory Assessment. Virginia: NSTA Press.

Duran, M., \& Dökme, İ. (2016). The effect of the inquiry-based learning approach on student's critical-thinking skills. Eurasia Journal of Mathematics, Science \& Technology Education, 12(12), 2887-2908.

Fogarty, R. (1991). How to Integrate the Curricula. United States of America: IRI/Skylight Publishing. Jannah, H. (2014). (Online). Diunduh dari digilib.uinsby.ac.id/398/5/Bab\%202.pdf pada 29 Desember 2017.

Joyce, B. \& Weil, M. (1992). Models of Teaching (Eight Edition). New Jersey: Prentice-Hall, Inc.

Karli, Hilda. 2003. Head-Hand-Heart dalam Kurikulum Berbasis Kompetensi. Bandung: Bina Media Informasi 
Kazempour, E. (2013). The effects of inquiry-based teaching on critical thinking of students. Journal of Social Issues \& Humanities, 1(3), 23-27.

Kemendikbud. (2013). Permendikbud No.65 tentang Standar Proses Pendidikan Dasar dan Menengah. Jakarta: Kementrian Pendidikan dan Kebudayaan.

. (2017). Model Silabus Mata Pelajaran Sekolah Menengah Pertama dan Madrasah Tsanawiyah. Jakarta: Kemendikbud.

2011. Panduan Pembelajaran IPA Secara Terpadu. Jakarta: Pusat Kurikulum.

Maxwell, D. O., Lambeth, D. T., \& Cox, J. (2015). Effects of Using Inquiry Based Learning on Science Achievement for Fifth Grade Students. Asia-Pacific Forum Science Learning and Teaching, 16 (2).

Maxwell, D. O., Lambeth, D. T., \& Cox, J. T. (2015, June). Effects of using inquiry-based learning on science achievement for fifth-grade students. In Asia-Pacific Forum on Science Learning \& Teaching, 16(1).

Muhafid, E. A., Dewi, N. R. \& Widiyatmoko, A. (2013). Pengembangan Modul IPA Terpadu Berpendekatan Keterampilan Proses Pada Tema Bunyi di SMP Kelas VIII. Unnes Science Education Journal, 2 (1). 140-148.

Oludipe \& Idowu, D. 2011. Developing Nigerian Integrated Science Curriculum. Journal of Soil Science and Environmental Managemen, 2(8),134-145.

Rosidi, I. (2015). Pengembangan Perangkat Pembelajaran IPA Terpadu Tipe Integrated Untuk Mengetahui Ketuntasan Belajar IPA Siswa SMP Pada Topik Pengelolaan Lingkungan. Jurnal Pena Sains, 2(1), 14-25.

Rustaman, N (2003). Kemampuan Dasar Bekerja Ilmiah dalam Sains. Makalah pada Seminar Pendidikan Biologi - FKIP Unpas Bandung.

(2007). Asesmen dalam Pembelajaran Sains. Program Doktor Pendidikan IPA Sekolah Pascasarjana UPI. Bandung.

Server, D., \& Guven, M. (2014). Effect of Inquiry Based Learning Approach on Student Resistance in A Science and Technology Course. Educational Science: Theory and Practice.

Subarkah, C. Z., \& Winayah, A. (2015). Pengembangan keterampilan berpikir kritis siswa melalui process oriented guided inquiry learning (POGIL). Jurnal Pengajaran MIPA, 20(1), 48-52.

Sufairoh. (2016). Pendekatan Saintifik dan Model Pembelajaran K-13. Jurnal Pendidikan Profesional, 5(3). 116-125.

Sukini, S. (2019). Penerapan Pembelajaran Guided Inquiry Berbasis Pendekatan Saintifik untuk Meningkatkan Aktivitas dan Hasil Belajar Kognitif Biologi Siswa Kelas XI MIPA SMA Negeri 3 Dumai. Journal of Natural Science and Integration, 2(1), 105-121.

Surif, J., Ibrahim, N.H. \& Mokhtar, M. (2012). Conceptual Knowledge and Procedural Knowledge in Problem Solving. Science Direct, 56. 416-425.

Syafaren, A., Yustina, Y., \& Mahadi, I. (2019). Pembelajaran IPA Berbasiskan Integrasi Inkuiri Terbimbing dengan Numbered Heads Together (NHT) dalam Meningkatkan Motivasi Belajar. Journal of Natural Science and Integration, 2(1), 1-11.

Trianto, 2007. Model Pembelajaran Terpadu dalam Teori dan Praktek. Jakarta: Prestasi Pustaka.

Zuiker, S., \& Whitaker, J. R. (2014). Refining inquiry with multi-form assessment: Formative and summative assessment functions for flexible inquiry. International Journal of Science Education, 36(6), 1037-1059. 